\title{
Research on Construction of Industrial Park Management Platform Based on Cloud Computing
}

\author{
YANG Lin $^{1,}$, NIE $\mathrm{Yu}^{2}$ and ZHANG Yilai ${ }^{2}$ \\ ${ }^{1}$ Jingdezhen Ceramic Institute, Jiangxi, China \\ 2 Jiangxi Province Engineering and Technology Research Center of Ceramics Enterprise \\ Information, Jiangxi, China \\ ayanglin4016@126.com
}

Keywords: Industrial park, Cloud computing, Management platform

\begin{abstract}
An efficient management platform of industrial park can provide data analysis and data decision support, such as operation services as investment, property management, maintenance and security. However the construction of the management platform of industrial park is the key issue to assure that the platform is efficient. To address this issue, a new cloud-based construction of industrial park management platform is proposed in this paper. This paper, from the perspective of industrial park management, by introducing the concept of cloud computing, analyzes the needs and positioning of the park management platform, constructs a platform for the industrial park management based on cloud platform, explains the function of each module and illustrates the key technology and hardware structure of the platform construction.
\end{abstract}

\section{Introduction}

With the rapid development of economy, the competitions among enterprises are increasingly fierce and thus, the industrial park model typically characterized by industrial chain and industrial cluster has undergone rapid development. However, the traditional park management can hardly maximize the cluster advantages or follow the pace of the information age, let alone meet the requirements of enterprises to make rapid response to market changes. Therefore, how to make full use of Internet technology to effectively expand market space, strengthen internal management and improve enterprise services is becoming the new subject with which currently various types of industrial parks and middle and small-sized enterprises are confronted. First, the industrial park management platform is constructed to meet specific needs of the development of the enterprises in the park, such as policy guidance, work deployment and coordination of economic operation factors. Second, it can contribute to making rapid response to the data, information and major events of the park for the enterprises by establishing fast and convenient communication channels between the park and the enterprises. Additionally, it can satisfy the demands of the industrial park, such as administrative management, business management, communication scheduling, safety guarantee, etc. to reduce rehandling and promote the efficiency of the park. Last, it is conducive to achieving centralized and unified publicity of the park and enterprises on the information platform, the expansion of investment, the enhancement of visibility and influence as well as the acceleration of the development of the park.

Cloud computing is a computing mode based on Internet, which employs the Internet to make further data integration and operation so as to provide mass data storage and data service ability. In other words, cloud computing provides on-demand services and on-demand cloud services ${ }^{[1]}$. The cloud-based information service platform mainly adopts hierarchical structure design, including three levels, namely, Infrastructure as a Service (IaaS), Platform as a Service (PaaS) and Software as a service (SaaS). The biggest feature lies in the concept of "virtual space" which not only provides such things as platform and software service with network as basic carrier to accomplish efficient and coordinate work by integrating massive extensible calculation, data, storage and other distributed resources, but also implements distribution according to needs and elastic expansion to 
deal with the resources. Thus, the using spaces of the resources are maximized to achieve economies of scale.

\section{The planning and construction of industrial park management platform}

The construction of management platform based on cloud computing provides relevant information resource service which can effectively reduce informatization construction costs for enterprises in the park, achieve maximum intensification for park resources, enhance the level of informatization construction of the industrial park and offer decision support for park management and the development of enterprise operators development. Therefore, the industrial development of the entire park can be promoted. With the massive growth in the number of parks and park data as well as the increase in diversity of the data and service of each park, the establishment of the park cloud computing center is imperative. The establishment of the park cloud computing center is not only for the storage of vast amounts of information data, but also to further employ data mining technology which can unearth effective information from the mass data, providing reliable data for the park planning and enterprise development.

Requirements and positioning of industrial park management platform.

Industrial park management platform must keep close contact with service objects, conduct analysis from the perspective of informational requirements of the industrial park and additionally implement investigation of the service required by enterprises in the park. The service objects of industrial park informatization platform refer to the park developers, operating managers, the entered enterprises in the park, third-party service agencies and other financial companies and investors. This object presents different priorities in their demands for information service platform.

(1) The industrial park developers and operating managers: they need a management platform conductive to the business operations in the park to conduct orderly management of the various resources in the park and to grasp the business activities and external investment promotion of the various enterprises in the park. Thus, it can be referred to as industrial park management platform operator.

(2) Enterprises in the park: they need to have a good command of such information as basic information of the industrial park, infrastructure, transportation vehicle management and storage as well as the ancillary services and logistic support the industrial park provides.

(3) Third-party service agencies: what they need include the basic information of industrial park and enterprises in the park and their business scope so as to decide what third party service should be offered.

(4) Other companies and investors, referring to the companies and individual investors who have not entered but have this intention: they expect to know the basic information of the industrial park, occupancy costs, and the relevance to the enterprises in the park.

The objects of the industrial park management platform mainly involve the following three aspects: First, to satisfy the requirements of establishing efficient and convenient informatization for the daily operations of the park, and thus accomplish information integration; second, with the unified data exchange to achieve omni-directional integration of resources through the collection, processing, integration and sharing of the information resources inside and outside the park; third, through informatization of the platform and resource integration, to optimize park management model and operation philosophy, meliorate the operation quality of the enterprises in the park, integrate industry resources and promote the overall development of the park.

\section{Cloud architecture of the industrial park management platform.}

The industrial park management platform adopts hierarchical design, consisting of Infrastructure as a Service (IaaS), Platform as a Service (PaaS) and Software as a Service (SaaS) ${ }^{[2,3]}$. As shown in Figure 1: 


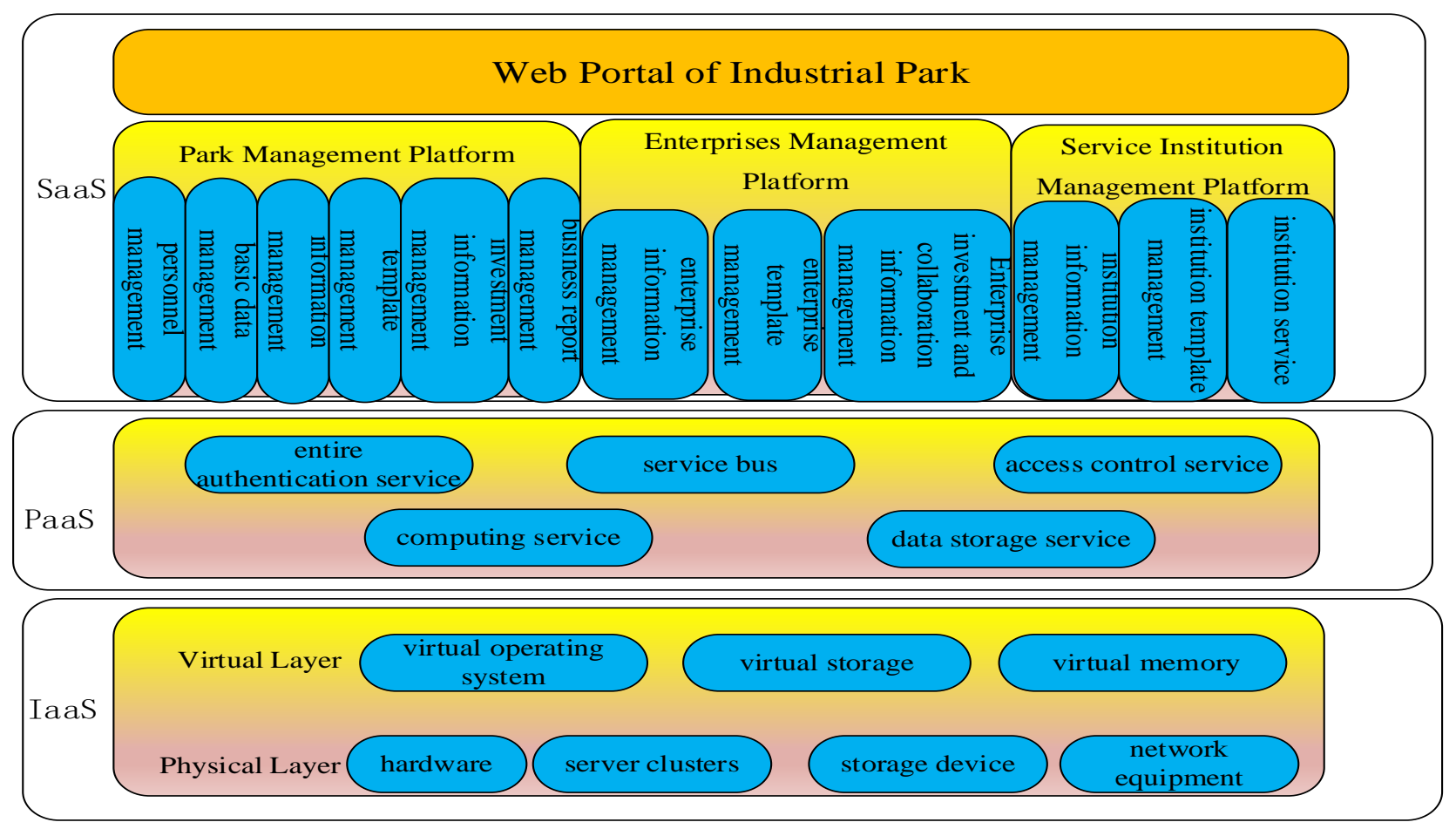

Fig.1 cloud architecture of industrial park management platform

(1) Infrastructure as a Service (IaaS layer)

Employing the IaaS model, Infrastructure as a Service mainly establishes virtualized hardware resource pools; this is the basic premise to support the operation of the industrial park management platform. This layer can be divided into physical layer and virtual layer, the physical layer includes all kinds of hardware needed by the platform, server farms, storage devices and network equipment; the virtual layer comprises virtual operating system, virtual storage and virtual memory. The operation mode of this IaaS layer is to form virtual clusters with the hardware resources of the virtual layer and the physical layer in order to support the upper applications and service layer to conduct high-performance computing and massive data storage, providing a safe and stable environment and massive storage space.

(2) Platform as a Service (PaaS layer)

Platform as a Service adopts PaaS model to form the managed environment, which implies by the integration and construction of the unified application support environment to quickly launch the Web application or service and to use the open interfaces for secondary development and application integration. This layer is composed of the kernel and basic services, business components, development support environment and etc.. Located between the IaaS layer and the SaaS layer, the PaaS layer provides the support of data and program service for the SaaS layer with strong service integration capabilities, including security certification services, computing services, data storage services, service bus and access control services and other hardware and software functions. This layer contributes to the accomplishment of multi-service model compatibility and resource sharing.

(3) Software as a Service (SaaS layer)

Software as a Service is to built SaaS layer application systems and programs related to industrial park management, and by using SaaS to achieve virtualization deployment and unified construction. This layer offers system applications which can meet the needs of the basic information service of the industrial park, and on this basis, provide to the park developers and operating managers, the enterprises in the park, third-party service agencies and other financial firms and investors as required.

\section{Overall architecture of the industrial park management platform.}

The overall architecture of industrial park management platform contains four layers of system: business logic layer, core classes, base and extended classes, kernel among which the business logic layer functions as management platform and with the help of core classes accomplishes data 
exchange and data storage. Whereas, core classes are an independent function module based on the core classes and the base classes which simplify the development process of the platform ${ }^{[4,5]}$. The Overall architecture of the platform is shown in Figure 2.

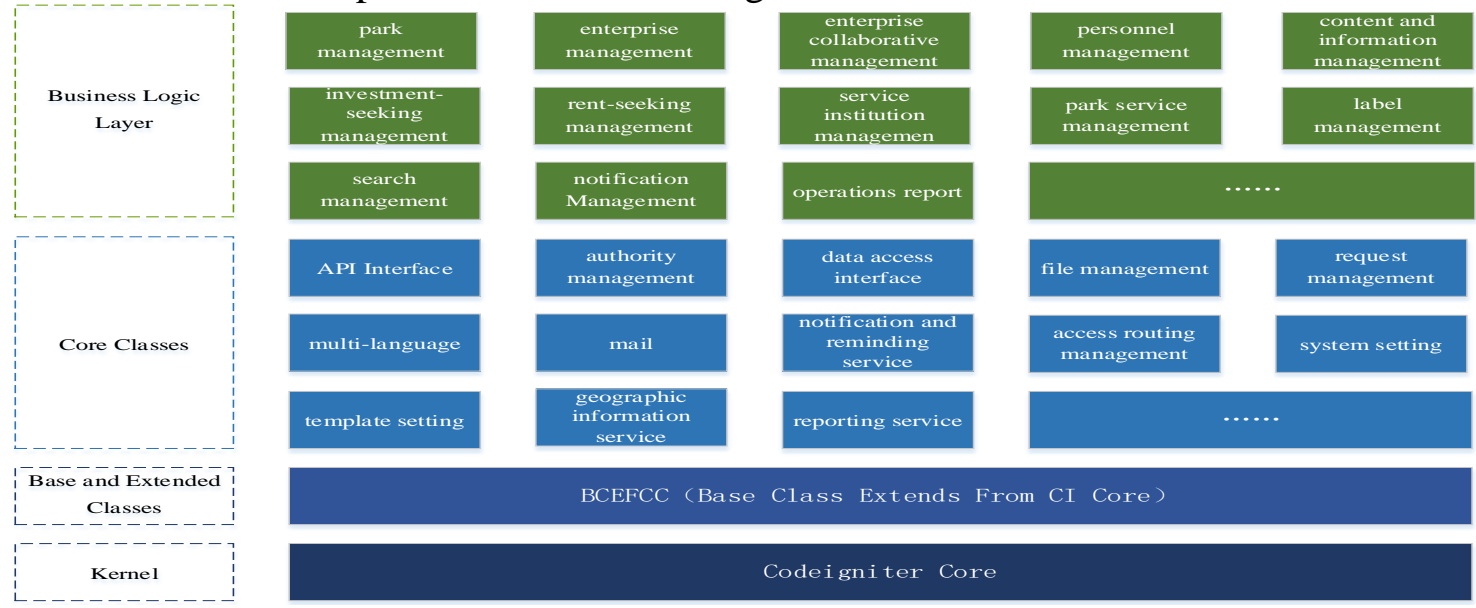

Fig.2 overall structure of industrial park management platform

\section{Structural design of industrial park management platform.}

With the development of technology, the mobile clients are increasingly popular. Hence, in order to satisfy the requirements of industrial and achieve convenient and efficient real-time management, the park management platform strives to meet the needs of cross-platform which means establish management interface which can be simultaneously used by PC clients and mobile clients and share platform data. The platform structure is shown in Figure 3.

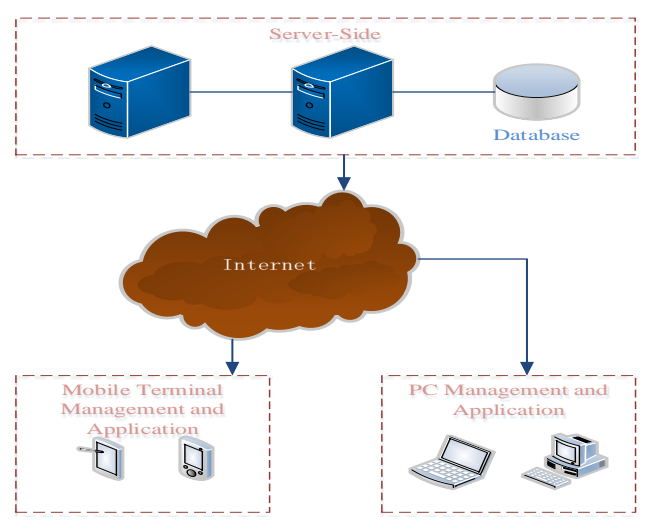

Fig.3 industrial park management platform structure

\section{The function module design}

Based on the foregoing analysis of the overall structure and architecture of the park management platform, combined with practical management experience of the industrial park, the park management platform is divided by function into file management, data auditing, template management, website management, platform settings, label management, report management, investment-seeking and rent-seeking management, content and information management and the like, whereas according to the user types, it can be divided into park management, enterprise management, service institution management. The details are shown in Figure 4. 


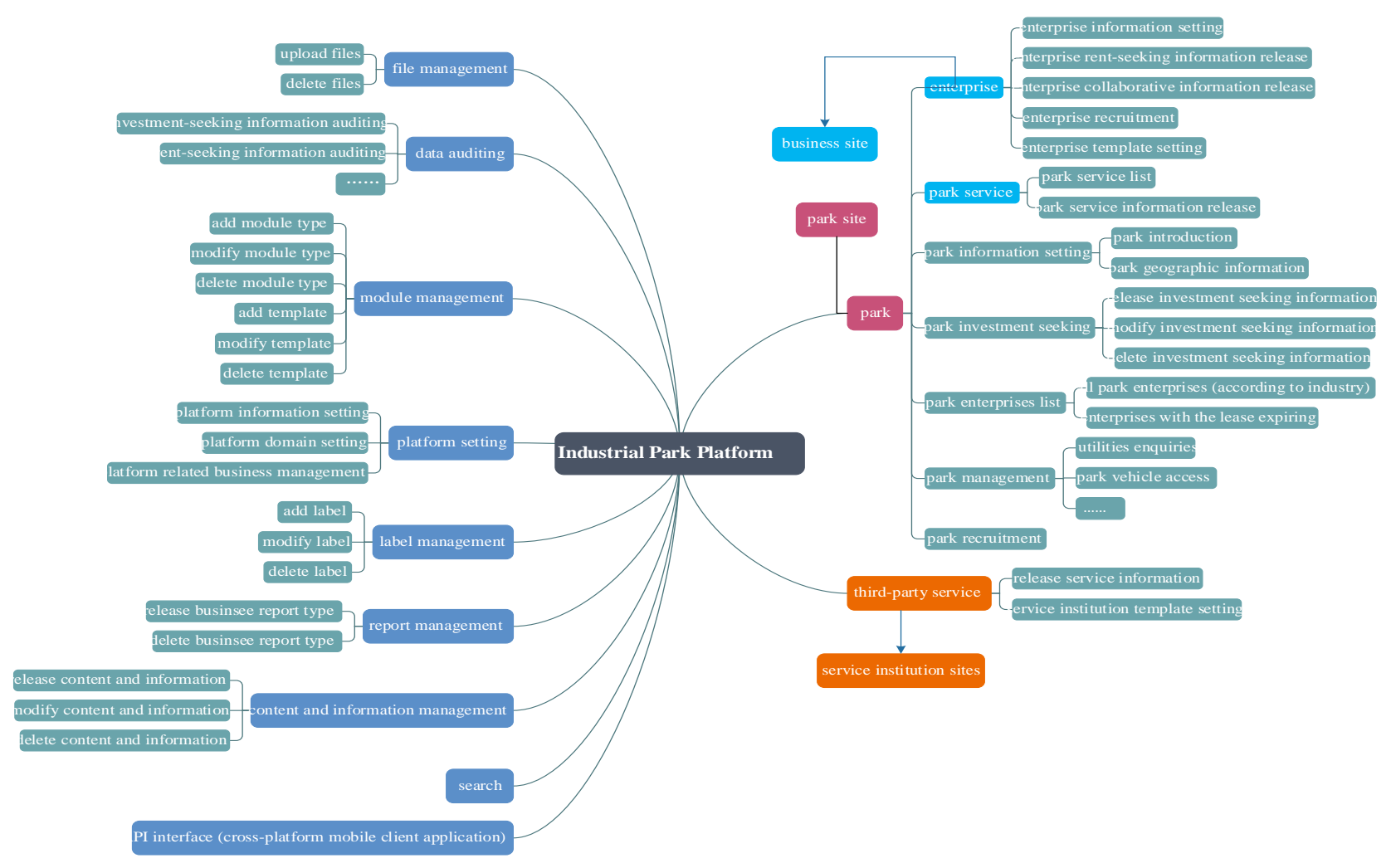

Fig.4 functional diagram of industrial park management platform

\section{Park management.}

(1) Park (permissions) personnel management

Permission assignment of park management mainly deals with the assignment of persons in charge of relevant business, such as the person in charge of access control, the person responsible for the dissemination of information to attract investment.

(2) Park basic data Management

This section handles the basic data management of the park, such as introduction of the park, plane drawings of the park and the factory building, park features, geographical location of the park and other related data.

(3) Park information Management

It consists mainly of publication of news inside the park, the release and management of notification message.

(4) Park template management

This section mainly includes the management of industrial park templates and the skin setting of the park site.

(5) Park investment information management

This section mainly deals with the dissemination and management of the investment information of such infrastructure as factory buildings and services.

(6) Park investment business report management

This section contains statistical report of investment business inside the industrial park, basic information reports of the settled enterprises.

\section{Enterprise management.}

(1) Enterprise information management

This section mainly comprises management of enterprise data, such as business reports and enterprise features.

(2) Enterprise template management

This is mainly employed by enterprises to establish independent websites, including template management, navigation menu and skin of enterprise websites.

(3) Enterprise investment and collaboration information management 
This section is designed for the release and management of enterprise investment information as well as the inter-enterprise collaborative information, such as recruitment, product supply and demand, and equipment rental.

\section{Service institution management.}

The function of service institution management is roughly the same with that of enterprise management and the main distinction lies in the fact that service institution put more emphasis on highlighting the public services provided to the park and grasping the public services expected by the park.

\section{Key Technologies and hardware architecture of industrial park management platform}

The park management platform employs B/S architecture, SOA software architecture, business engine, search engine, form engine, enterprise portals, HTML5 cross-platform technology and clients applying PHP/HTML5/jQuery technology. To access the platform, what PC users need is only a browser (IE8+, chrome, Firefox, etc.), while the mobile clients simply need to install the App of this platform without installing other plug-ins. The platform deployment takes a full consideration of the park management requirements both in short-term planning and in long-term planning. Therefore, by adding servers or disk arrays, the hardware of the platform can be expanded. The hardware architecture is shown in Figure 5.

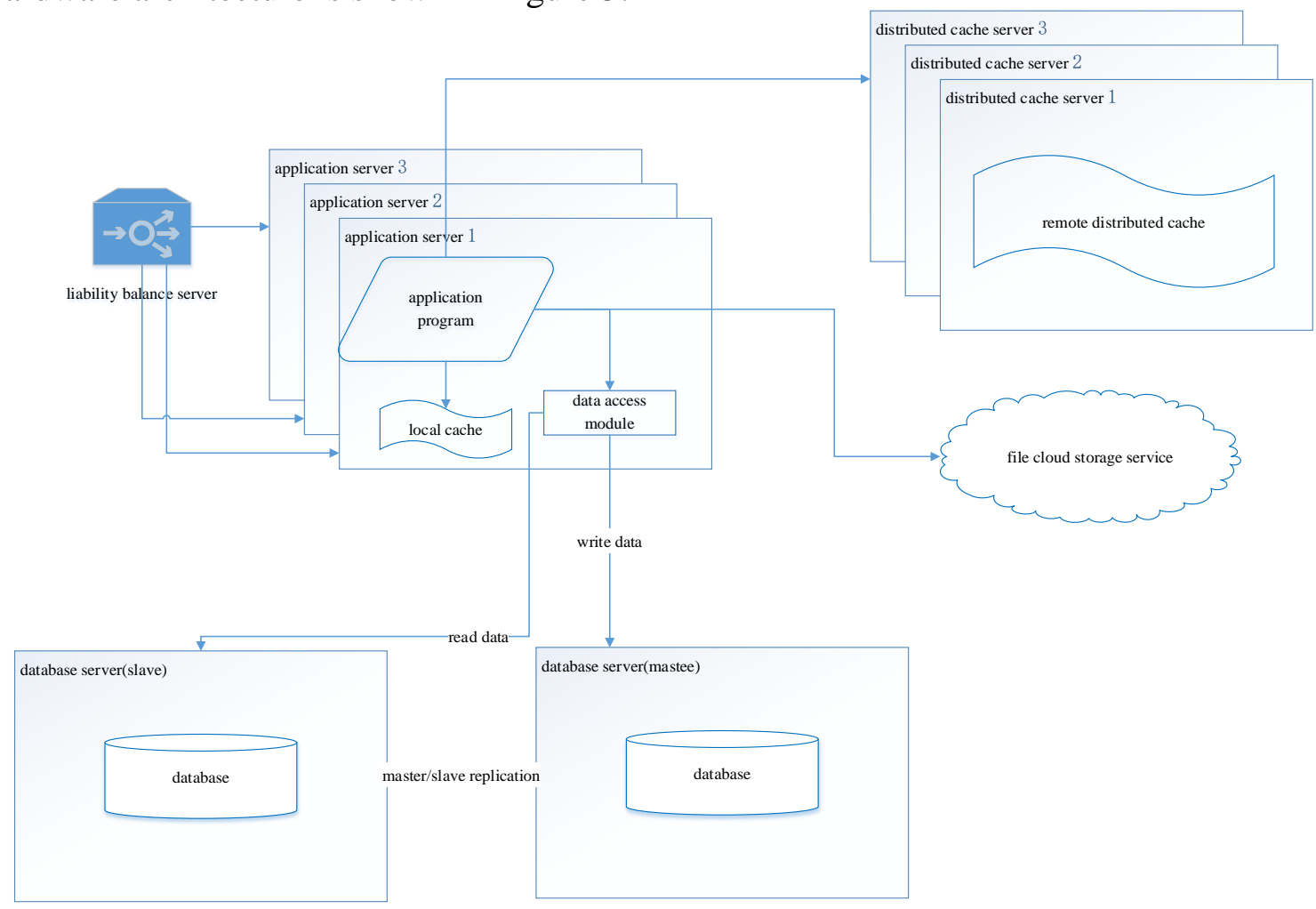

Fig.5 server architecture deployment diagram

\section{Conclusion}

The industrial park management platform proposed in this paper employs cloud computing as the foundation of architecture and based on the three type modules: park, enterprises in the park, third-party service personnel, the unified platform is constructed to integrate information and resources within the industrial park and to satisfy the informational requirements of the park operational managers, enterprises in the park, third-party service agency and other financial companies and investors, accomplishing data exchange and information sharing among all the elements. Meanwhile, the paper attempts to illustrate the key software and hardware technology applied in the process of platform construction and expects to provide technical support for the practical platform construction. 


\section{References}

[1] Peng Liu: Cloud Computing (Second Edition). Beijing: Electronic Industry Press ( 2011).

[2] Yunxia Han: Construct Regional Logistics Information Platform Based on Cloud Model Research. Logistics Engineering and Management, Vol. 12 (2014), p. 70-71.

[3] Xuan Qiu, Hao Luo and Gangyan Xu: Physical assets and service sharing for IoT - enabled Supply Hub in Industrial Park (SHIP), International Journal of Production Economics, Vol. 159 (2015), p. 4-15.

[4] Monika Mital, Ashis K. Pani, Suma Damodaran, Ram Ramesh: Cloud based management and control system for smart communities: A practical case study, Computers in Industry, Vol. 7 (2015), p. 1-11.

[5] Yu Yang: Build Cloud-based Operating Platform Networking Analysis and Research, Computer Knowledge and Technology, Vol. 9 (2013), p. 8189-8191. 